\title{
NATURE PROTECTION IN INDONESIA
}

\section{By A. Hoogerwert, Head of the Department of Nature Protection and Wild Life Management}

(A summary of a report written for the Pacific Science Congress, Manila, November, 1953.)

The period from 1942 till 1950.-During the Japanese occupation of Indonesia, the damage to the protected fauna and flora was not catastrophic. The capture of animals for export came to a standstill and the possession of fire-arms was prohibited. Before the war, in Java alone, there were more than 60,000 registered hunting rifles, not to mention un-registered rifles. On the other hand illegal clearing of forest ran riot during the occupation and unlawful hunting without firearms became common. Nevertheless more damage to fauna and flora was done from 1945 till the end of 1949 - that is after the Japanese occupation. But even this period of chaos and lack of the slightest spark of interest in nature conservation, did not lead to irreparable damage to game reserves or to wild life.

The present situation.-From the foregoing optimistic remarks, it must not be concluded that all is well, for very much remains to be done.

In spite of general understanding of the measures which ought to be taken, it will be a very long time before what has been accomplished can stand the test of even moderate criticism. It is true that besides the department for nature protection and wild life management at the Botanical Gardens, a special department has been established within the Forestry Service. But the influence which these are able to exercise on the practical execution of the laws and regulations, is next to nothing ; for they have been given no executive power. Moreover they have no means of training a staff or of giving its members, when trained, the material prospects which are indispensable for their retention. There is also a lack of both officials and private people with any knowledge of nature, so that it has not been possible to re-establish the pre-war hunting committees. An association for nature protection is also badly needed.

Everything being done for wild life protection to-day is the work of a few specialists. The management of reserved areas is entrusted to the superintendents of the Forest Service and to certain officials of the Civil Service, but without the budget necessary to perform their task. 
Regulations concerning Nature Protection and Hunting.-All pre-war laws and regulations in this field from before the war remain valid, but on account of the depreciation of the currency the hunting tax is increased by from 500 to 1,000 per cent.

The lares now valid are:-

A. Nature protection.

(1) Wild Animals Protection Ordinance, 1931 (Protection of wild animals and birds).

(2) Regulations by virtue of the Wild Animal Protection Ordinance, 1931.

(3) Nature Monuments and Game Reserves Ordinance, 1932. B. Hunting.

(1) Game Hunting Ordinance for Java and Madura, 1940.

(2) Regulations by virtue of the Game Hunting Ordinance for Java and Madura, 1940.

By virtue of these regulations nearly 120 nature monuments and game reserves came into existence covering an area of almost $2,300,000$ ha. $(8,900$ sq. miles $)$. They are partly under the management of the Forestry Service, partly under that of the Ministry of the Interior (Civil Service). Only some of these reserves are guarded; nearly all have no attention at all, though the appointment of nature-protection officials at some forestry superintendents' offices gives an opportunity for paying some attention to these areas. The most important thing for the time being is to check poaching and to prevent unlawful clearing with or without the establishment of human settlements.

Export Permits and Hunting Licences.-As a further consequence of these laws a great number of mammals and birds, together with the giant lizard of Komodo, are protected and their capture or possession without a permit prohibited. The distribution of such permits and those for the export of the protected fauna and large quantities of non-protected animals are in the hands of Kebun Raya Indonesia (Botanical Gardens). The distribution of hunting licences is entrusted to the police authorities who have no knowledge of wild life management or hunting, but we are grateful that the chaotic situation of the last few years has been stopped. During that period hunting was carried on without licences and without paying a penny for shooting the finest game.

Propaganda.-A considerable sum of money was put at our disposal for instruction and propaganda purposes. This made it possible to present to the public a large coloured poster showing 
twelve different birds useful to agriculture, accompanied by a small booklet for class use. Some thousands of these posters were distributed free of cost and there are demands for many thousands more. This poster was followed by an illustrated manual of instruction containing all regulations on nature protection and hunting, and a map. Though the price is rather high, nearly 1,500 have been sold during the two first months of its existence. It was published with the main purpose of making the officials concerned with these matters conversant with the regulations.

As a third project more than half a million receipt stamps went into circulation. They are printed in colours and show pictures of four different species of protected mammals and four of protected birds. Slogans on every stamp encourage nature protection. Two calendars are also in print with the object of attracting attention to nature protection and wild life management. With the exception of the booklet all this material is at the disposal of the public without cost except postage.

Further funds were granted to make Kodachrome films of some important reserves. The original copies of two films are nearly ready but owing to the high cost of production, it will be some time before copies can be distributed.

The Reserved Areas.-There is no reason whatever to suppose that nature protection and wild life management in this country receive less attention now than before the war. In fact never before could so much be done for instruction and propaganda, nor for the management of the national game reserve, Udjung Kulon, the last stronghold of Rhinoceros sondaicus. The same can be said for the famous bird sanctuary Pulau Dua. Both these reserves are permanently guarded by people living within their boundaries; similar measures are planned for some other reserves, though execution of such plans is very expensive.

\section{Protected Animals}

Orang-Utan (Simia satyrus).-We may assume that great numbers of orang-utan were smuggled to Singapore and other places during the period of 1946-1950. The constantly increasing prices on the world market of this species since 1951, however, gives reason to suppose that this trade has come to a stop or decreased considerably. This may be partly due to the better supervision of exports, for catching orang-utans without export possibilities has little or no meaning; partly also due perhaps to the high profit to be obtained by smuggling such products as rubber, tobacco and pepper. There are no indications of an 
early extermination of this ape or reasons to suppose that orangutans are rarer now than before the war, either in Sumatra or in Kalimantan (Borneo). Nevertheless Simia satyrus remains a species which we must keep under close observation and our efforts will be directed to give this animal all possible protection, both within the reserves and outside them.

The Rhinoceroses.-We have very little information about the rhinoceroses, except from the Udjung Kulon reserve on the most westerly peninsula of Java, where Rhinoceros sondaicus is under regular observation by the author of this report.

The very extensive, often inaccessible forest complexes in Sumatra and Kalimantan where the Sumatran rhinoceros, Dicerorhinus sumatrensis is living, seem to give this species a good chance of survival. But I, personally, am not of that opinion, for there are always many poachers ready to penetrate into the heaviest jungle to acquire such a valuable animal as the rhinoceros, and it is not necessary to catch the animals alive. Even the dead body has a high commercial value, for the flesh and other parts of this ill-fated creature are supposed to be a cure for all kinds of diseases. For this " medicine" people, especially the Chinese, will pay the highest price especially when supply is short, and we cannot be optimistic about the animals' future.

When considering the position of the Javan Rhinoceros (Rhinoceros sondaicus), the second species of rhino living in Indonesia, the situation seems still worse, again excepting the Udjung Kulon reserve. There is nothing to contradict the findings of some observers before the war that this rhinoceros had disappeared from Sumatra. It seems indeed the truth that the last specimens outside Java were shot by a European hunter, in the southern part of Sumatra about 1934.

The Javan rhinoceros is however present and thriving rather well, as far as I can discover, in Java itself; that is in the Udjung Kulon reserve, an area of about 35,000 ha. (135 sq. miles). Their numbers do not exceed 30 or 40 . During my last expedition to this reserve, in September, 1952, I met a pair of these rhinoceroses and on two other occasions during the same trip, I found indications that the animals were in pairs. Along a patrol-path of only a few miles long, there were spoors of at least three different rhinoceroses which had been walking there during the same night. At three different points in the reserve guards are living with orders to patrol at irregular intervals. Moreover there is a regular movement of Forestry Service men, between the populated areas of Bantam and the reserve, so that poachers have only a very small chance of success. At least ten rhinos 
from this area and the surrounding regions were slaughtered during the years 1946-1951, but no cases have since come to our knowledge.

There is much to be done before we can say that Rhinocerus sondaicus will be saved from extinction. There are even now several Chinese "druggists" in Djarkarta and other towns who display life-size paintings of this rhinoceros, offering for sale the medicaments prepared from it. This is possible in spite of the fact that the animal has been protected for many years, which implies that the possession of any part of it is punishable by law !

Giant Lizard of Komodo (Varanus komodoensis).- - A recent visit to the islands of Komodo, Padar and Rintja, the habitat of the giant lizard, showed that the species was thriving well and we think that their numbers have not decrcased since about 1940. The animals on which they prey, principally deer and pig, were met with plentifully in many localities and the same can be said of the monkeys on which the smaller specimens seem to prey on the island of Rintja. When we add to this that there are also large areas in West-Flores where these giant lizards are living, there seems no reason whatever to think of their becoming extinct. But in the neighbourhood of the village of Komodo and on the uninhabited island of Padar, domestic dogs left by native hunters have run wild and kill the deer and pig. In consequence, within 10 or 20 years the island of Padar will have no deer and therefore no giant lizards.

The Elephant (Elephas maximus).-The situation of the Sumatran elephants seems less favourable than ever before, mainly because they come into contact with almighty man, who penetrates further and further into their habitat. Though some years ago elephants were considered outlaws, there are signs now of sympathy for our standpoint, which is to drive away elephants by other means than bullets, put into any convenient part of the poor creatures' bodies. It might be of some use to try the feeble-current electric installations which are under trial elsewhere. Reports about this apparatus will be very welcome to the present author.

The problem of elephant preservation is one of the most difficult conservation problems, and not only in Indonesia I think.

Other protected animal species.-Regarding other protected animal-species such as tapir, proboscis monkey, gibbons, goatantelope of Sumatra, birds of paradise and other birds, there are no reasons to believe that the situation is worse than before the war. Most of these animals have only export-value 
and the profit from export does not equal the trouble of catching them, certainly not so long as there are so many other easier and less risky ways of getting money.

The protected animals, dead or alive, which leave this country in a legal way are reduced to a minimum. This is possible because the responsibility for export licences rests with our department.

\section{Game Animals}

The position of the game animals in Java and elsewhere in Indonesia, banteng (wild ox), deer, barking deer, pig, Java tiger and panther leaves much to be desired in certain places, but seems to be satisfactory elsewhere.

The Bawean Deer (Cervus kuhli). - It may be doubted whether the rare deer Cervus kuhli, only known from the small island of Bawean, still exists, but that question could be put also in the pre-war years, for it is a very long time since critical observers really saw this animal. It will be our purpose in an expedition next year to find out if this beautiful deer is still alive and to make a second trip to the Kangean Archipelago to investigate the deer population of that region.

The Banteng or Wild $O x$ (Bos banteng).--Generally speaking the Javanese wild ox has decreased outside the reserves though in some localities there are reports to the contrary. Inside the reserves the same is true partly because of poaching, partly owing to neglect of pastures necessary to maintain a good food supply. The stock of banteng in the Baluran reserve, east Java, is about 100 head and that in Udjung Kulon 200 to 250. This means half or less than half as many animals as before the war. But the female and young banteng in Udjung Kulon are in a better condition than in pre-war years. It is now an exception to see a cow without a calf of the year and she often has a calf of the previous year with her also. However, many banteng especially bulls, never reach full weight, for one seldom meets even an adult bull of 800 or 850 kilos. From a veterinary examination made in 1938 it is clear that this may be partly caused by Distomatosis infections (Liverfluke, Ed.), a disease which is very difficult to cure under these conditions. We have tried to improve the situation by opening more pastures in higher and drier places, but there are so many shallow marshes in the reserve, especially during the wet monsoon, that it will be very difficult to banish Distomatosis altogether. In this respect, as in that of electric fencing, suggestions of specialists will be very welcome. There are no indications that this illness has fatal consequences to the number and quality of the calves, and veterinarians are 
of the opinion that the death-rate does not rise provided the food supply is sufficient.

Of the game reserve Tjikepuh (before the war under private management of an association of big-game hunters) little is known, but some reports give reason to suppose that the number of banteng have considerably decreased, and much the same can be said of the Leuweung Santjang forest reserve. The contrary is the case with the Panandjung game reserve, central Java, where the stock of wild oxen has increased. Alas! this is a stock of cross-bred animals, not of much value.

Common Java Deer (Rusa timorensis russa).-Deer in the Udjung Kulon reserve are more plentiful than in pre-war times. From about 75 head, shortly before the war, they have increased to 200 or 250 , of which a good percentage are calves. The number of deer in the Saluran reserve, east Java, is not known to me ; it seems that there are less now than before the war. Of the more than 10,000 deer once living in the private reserve Yang Highland, east Java, only some hundreds are left now.

Several of the above-mentioned reserves can not yet be taken into regular management, but the Forestry Service strives to prevent a further depletion of the game-stock.

Java Tiger (Felis tigris sondaica).-Of the Java tiger little is known. It may be that this beast of prey can maintain itself for a long time to come, but it is our opinion that the species is, next to the Rhinoceros sondaicus, the most threatened animal of Indonesia. Perhaps it survives only in the Udjung Kulon reserve where it enjoys the same protection as all other animals. In my opinion tiger decreased in the said reserve after the war. This may have been caused by some disease, for shortly before the Japanese invaded Java I saw, within two years, the remains of three dead tigers, hardly a common sight. It is difficult to propose protective measures on behalf of the tiger other than those in the game reserves, for there are few places where the tiger can be tolerated in an island so full of human beings as is Java. 